Special issue of the 3rd International Conference on Computational and Experimental Science and Engineering (ICCESEN 2016)

\title{
Mechanical Properties of Soda-Lime-Silica Glasses Doped with Eggshell Powder
}

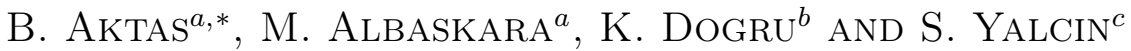 \\ ${ }^{a}$ Harran University, Mechanical Engineering Department, Sanliurfa, Turkey \\ ${ }^{b}$ Harran University, Institute of Natural and Applied Sciences, Sanliurfa, Turkey \\ ${ }^{c}$ Harran University, Physics Department, Sanliurfa, Turkey
}

\begin{abstract}
In this study, eggshell powder obtained from eggshell waste was used as a dopant in soda-lime-silica glass powders. Various eggshell-doped soda-lime-silica glass samples were produced through melting, and the effect of the eggshell powders on the mechanical properties of the soda-lime-silica glasses was investigated by microVickers indentation tests. The X-ray diffraction results of the eggshell-doped glasses showed that, depending on the dopant content, different phases such as gypsum, nepheline, alunogene, aragonite, cristobalite etc. appeared. These results were different from the X-ray diffraction patterns of pure soda-lime-silica glass powders, where the phases observed included sodium aluminium silicate, sodium aluminum oxide, and silicon oxide. Although the elastic modulus of soda-lime-silica glasses increased with the addition of the eggshell powders, the dopant powders also caused an increase in the hardness of the glasses. Furthermore, it was found that the fracture toughness increased for soda-lime-silica glasses with 0.5 and $1 \mathrm{wt} \%$ eggshell powder, while it decreased for samples with eggshell powder contents $\geq 1 \mathrm{wt} \%$. This behaviour could be explained by an increased depolymerization in the network connectivity of the glass when the amount of eggshell dopant increases.
\end{abstract}

DOI: 10.12693/APhysPolA.132.436

PACS/topics: soda-lime-silica glasses, eggshell wastes, mechanical properties

\section{Introduction}

Glass is one of the most brittle materials known, and in fact, the catastrophic mechanical failure of glass is often attributed to its high brittleness. In spite of this, brittleness has been the least studied mechanical property of glass. However, studies on the brittleness behaviour of glass have become particularly important because recently, the demand for lightweight glass has risen as a result of its application in many products such as building materials, automobiles, bottles, displays, etc. [1]. Lightweight glass is typically obtained by decreasing the thickness of regular glass; however, as the thickness of these glasses decreases, so does their strength, thus creating a serious problem for their applicability [2]. Therefore, it is not surprising that the fragility of thin glasses has gained technological and industrial interest, as industries and scientists look for ways to produce usable, lasting, and resistant thin glasses [3, 4].

Lightweight glasses made up of soda-lime-silica $\left(\mathrm{Na}_{2} \mathrm{O}-\mathrm{CaO}-\mathrm{SiO}_{2}\right)$ are often used in furniture, houses, automobiles, packaging, etc. However, $\mathrm{Na}_{2} \mathrm{O}-\mathrm{CaO}-\mathrm{SiO}_{2}$ glass materials are brittle at room temperature, and therefore their manufacturing and engineering design becomes problematic because of their susceptibility to brittle cracking. Regarding the "brittleness" of $\mathrm{Na}_{2} \mathrm{O}-\mathrm{CaO}-$ $\mathrm{SiO}_{2}$ glass systems, Sehgal et al. [2] developed what they termed a "less-brittle" $\mathrm{Na}_{2} \mathrm{O}-\mathrm{CaO}-\mathrm{SiO}_{2}$ glass. Their

*corresponding author; e-mail: baktas@harran.edu.tr work brings to light the topic of glass "brittleness", how it is defined and measured, and to what extent it can be correlated to other glass characteristics, such as crack initiation. The objective of the present study, therefore, is to investigate the effects of eggshell (ES) powder on the mechanical and structural properties of soda-limesilica (SLS) glasses, as determined using a micro-Vickers hardness tester and an ultrasonic flaw detector.

\section{Materials and procedure}

In this study, SLS powders were used as the matrix material, and ES powders were used as dopants. SLS and ES powders were prepared by grinding SLS glasses (Trakya Glass Industry Co.) and ES waste, respectively. The chemical compositions of the powders used in the study are given in Table I.

TABLE I

Chemical composition [wt\%] of powders used in the study.

\begin{tabular}{c|c|c|c|c|c|c|c|c|c}
\hline \hline Powder & $\mathrm{SiO}_{2}$ & $\mathrm{Al}_{2} \mathrm{O}_{3}$ & $\mathrm{CaO}$ & $\mathrm{K}_{2} \mathrm{O}$ & $\mathrm{Fe}_{2} \mathrm{O}_{3}$ & $\mathrm{MgO}$ & $\mathrm{MnO}_{2}$ & $\mathrm{Na}_{2} \mathrm{O}$ & $\mathrm{TiO}_{2}$ \\
\hline $\mathrm{SLS}$ & 71.5 & 1.5 & 9.5 & - & 0.024 & 2 & - & 15.5 & 0.08 \\
$\mathrm{ES}$ & 0.03 & 0.0163 & 98.43 & 0.2186 & 0.0036 & 0.936 & 0.00435 & 0.363 & -
\end{tabular}

The SLS powders were doped with different ES powder amounts $(0.5,1,3$, and 5 wt\%) via mechanical mixing, using an Attritor type mixer at $200 \mathrm{rpm}$ for $1 \mathrm{~h}$. The powders were then pressed at $250 \mathrm{MPa}$, using a singleaxis die with a radius of $32 \mathrm{~mm}$, to produce pellets of a $32 \mathrm{~mm}$ diameter and $6 \mathrm{~mm}$ thickness. The glass samples were prepared via melting of the pressed pellets in a graphite mould at $1300^{\circ} \mathrm{C}$ for $2 \mathrm{~h}$ to ensure homogeneity, followed by quenching. The pellets used to make the 
glasses included undoped pellets (as control), and the different ES-doped SLS pellets.

After quenching, the samples were formed in a square graphite mould at $1100{ }^{\circ} \mathrm{C}$, then annealed at $500^{\circ} \mathrm{C}$ for $3 \mathrm{~h}$, and lastly slowly cooled to room temperature inside the furnace.

To investigate the microstructural and mechanical properties of the samples, the surfaces of the samples were successively ground using 120, 240, 400, 600, 800 and $1200 \mathrm{SiC}$ grinding papers, and finally polished using 6,3 , and $1 \mu \mathrm{m}$ diamond suspensions. The different phases present in the samples were obtained with a Rigaku D/max 2000 X-ray diffractometer, using $\mathrm{Cu} K_{\alpha}$ radiation in the $3-60^{\circ} 2 \theta$ range at a $3^{\circ} / \mathrm{s}$ scan speed, together with the "Jade" software. The density of the samples was determined using the Archimedes principle with distilled water.

The elastic modulus values of the produced glasses were obtained by measuring the longitudinal and transverse ultrasonic wave velocities in the glass samples using a Starmans Dio 1000 SFE. Both the hardness and fracture toughness of the specimens were determined using a micro-Vickers hardness tester using a load of $4.9 \mathrm{~N}$ for a $10 \mathrm{~s}$ testing time. The hardness values were calculated using the following equation:

$$
H_{v}=\frac{1854 P}{d^{2}},
$$

where $P$ is the applied load $(\mathrm{N})$, and $d$ is the mean value of the diagonal length $(\mathrm{mm})$. The fracture toughness values were calculated by measuring the lengths of the cracks that formed at the edges of the track due to the hardness tests. The cracks were measured immediately after applying the load to the specimen so that they would not be affected by environmental factors. The fracture toughness was calculated using the "half-pennycrack" formula proposed by Anstis et al. [5]:

$$
K_{I C}=0.016 \sqrt{\frac{E P^{2}}{H_{V} C^{3}}},
$$

where $E$ is the Young modulus, $H_{v}$ is the Vickers hardness, $P$ is the applied load, and $C$ is the crack length. The brittleness values $(B)$ were calculated from the measured $H_{v}$ and $K_{I C}$ values using,

$$
B=\frac{H_{V}}{K_{I C}} \text {. }
$$

\section{Results and discussion}

The X-ray diffraction (XRD) patterns of SLS glasses doped with ES powder $(0.5,1,3$ and $5 \mathrm{wt} \%)$ are shown in Fig. 1, where it can be observed that pure SLS and $0.5 \mathrm{wt} \%$ ES-doped SLS did not form any a crystalline phases, and had amorphous structures. When the ES powder content was $\geq 1 \mathrm{wt} \%$, different phases occurred, such as gypsum, nepheline, alunogene, aragonite, cristobalite, gehlenite etc., in the amorphous glass structure.

Figure 2 shows the effect of the ES powder content on the hardness and fracture toughness of SLS glasses,

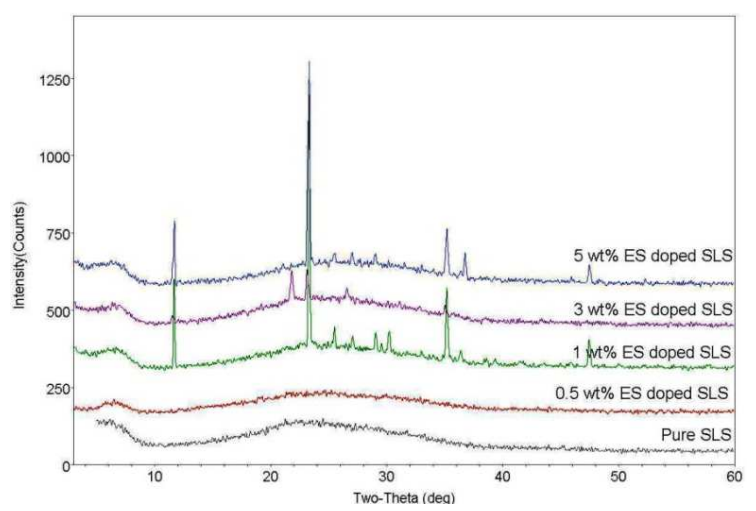

Fig. 1. X-ray diffraction patterns of SLS glass samples doped with ES powder.

where it is observed that the hardness of the SLS glasses increased due to the high amounts of $\mathrm{CaO}$ (a network modifier) in the ES powder. Furthermore, the fracture toughness of the SLS glasses increased as the amount of dopant, i.e. the ES powder, increased up to $1 \mathrm{wt} \%$. Higher dopant amounts resulted in a decrease in the fracture toughness of the SLS glasses, which could be the result of an increase in the strength of $\mathrm{Si}-\mathrm{O}-\mathrm{Si}$ bonds with $\mathrm{CaO}$, due to an increase in the polymerization degree of the glass network [6]. Therefore, SLS glass samples with high $\mathrm{CaO}$ contents $(3-5 \mathrm{wt} \%)$ are prone to cracks that can easily propagate due to the formation of a greater number of bonds between the modifying cations and nonbridging oxygen. Thus, a high $\mathrm{CaO}$ content may cause a decrease in the fracture toughness of SLS glasses.

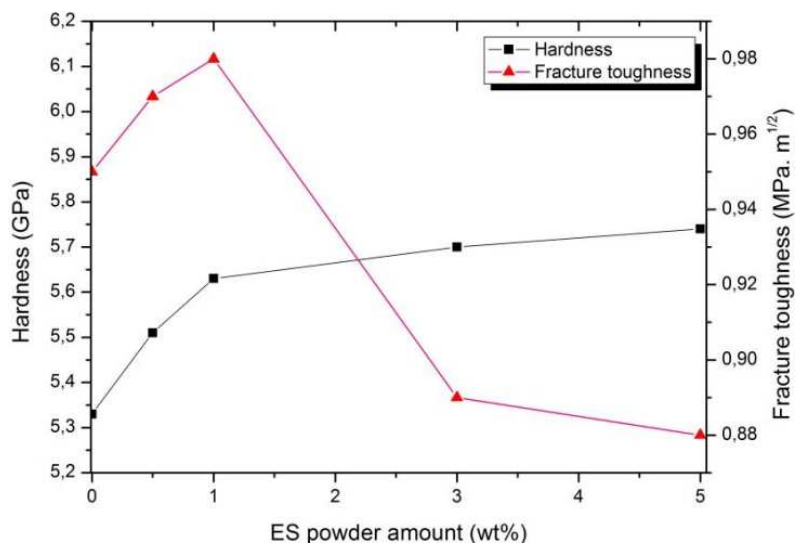

Fig. 2. Effects of ES contents on the hardness and the fracture toughness of SLS glass.

Table II summarizes the physical and mechanical properties of the glass samples. As the amount of $\mathrm{CaO}$ increased, the density of the SLS glasses increased due to the higher $\mathrm{CaO}$ density. The elastic modulus and hardness of SLS glasses increased as more ES powder was added, which is due to the strengthening of the glass network via network modifier cations $(\mathrm{CaO})$ present in 
the ES powders. The brittleness of glasses depends on densification, and on plastic deformation flow modes that occur before the crack initiation process [7]. Thereupon, the brittleness of the glass samples increased with increase of $\mathrm{CaO}$ content owing to a lesser densification of the samples.

TABLE II

Physical and mechanical properties of pure and ES-doped SLS glasses.

\begin{tabular}{c|c|c|c|c|c}
\hline \hline ES & $E[\mathrm{GPa}]$ & $\rho\left[\frac{\mathrm{kg}}{\mathrm{m}^{3}}\right]$ & $H_{V}[\mathrm{GPa}]$ & $K_{I C}[\mathrm{MPa} \sqrt{\mathrm{m}}]$ & $B\left[\frac{1}{\sqrt{\mu \mathrm{m}}]}\right.$ \\
\hline pure SLS & 79.93 & 2513 & $5.33 \pm 0.12$ & 0.95 & 5.61 \\
$0.5 \mathrm{wt} \%$ & 81.74 & 2521 & $5.51 \pm 0.21$ & 0.97 & 5.68 \\
$1 \mathrm{wt \%}$ & 83.55 & 2530 & $5.63 \pm 0.23$ & 0.98 & 5.74 \\
$3 \mathrm{wt} \%$ & 85.82 & 2546 & $5.70 \pm 0.16$ & 0.89 & 6.40 \\
$5 \mathrm{wt} \%$ & 89.84 & 2559 & $5.74 \pm 0.19$ & 0.88 & 6.52
\end{tabular}

Figure 3 shows the Vickers indentation imprints of undoped and ES powder-doped SLS samples. All the glass samples exhibited cracking at the four corners of the indent, which was induced by a $500 \mathrm{~g}$ load, for $10 \mathrm{~s}$, in air. Median and radial cracks were generally observed in the undoped and ES powder-doped samples (Fig. 3a-e).

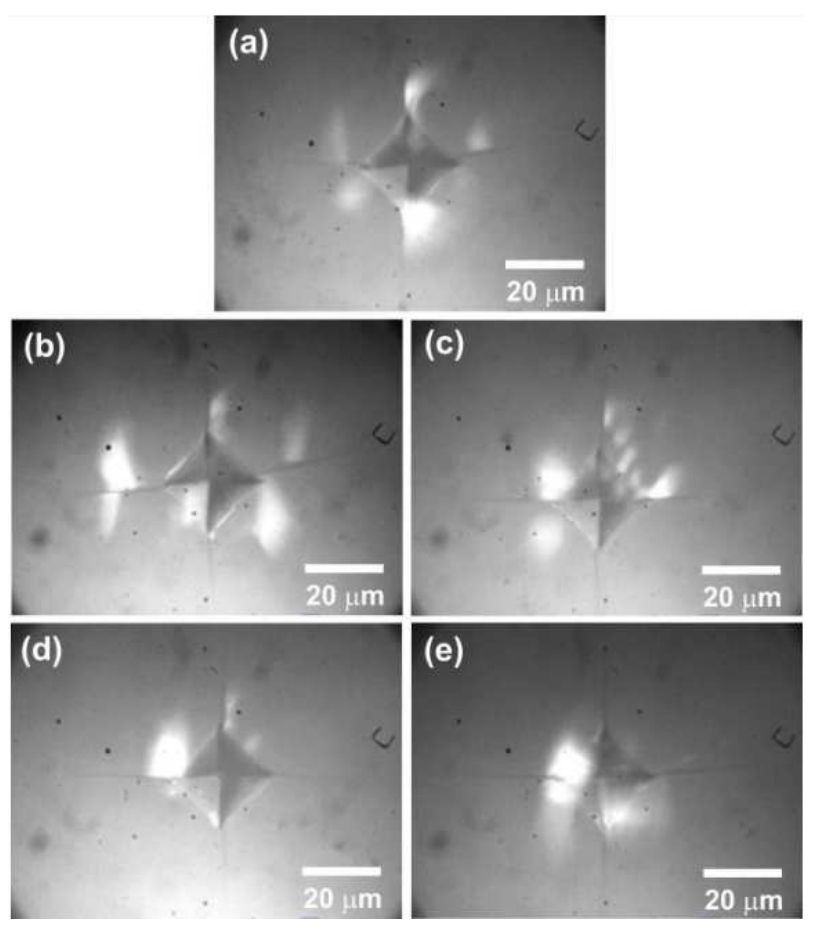

Fig. 3. Micrographs of Vickers indentations with different crack lengths of (a) undoped, (b) 0.5, (c) 1, (d) 3 , and (e) $5 \mathrm{wt} \%$ ES powder-doped SLS glasses.

\section{Conclusions}

In this study, ES-doped SLS glasses were produced by the melt-quench technique. The density of the SLS glasses increased with increasing dopant (ES-powder) content due to the high density of the $\mathrm{CaO}$ present in the ES-powder. It was found that ES-powder induced an increase in the hardness, fracture toughness, and elastic modulus of SLS glasses, owing to an increase in the polymerization degree of the glass network. The brittleness of the glasses increased with increasing $\mathrm{CaO}$ content due to a lesser densification of the samples.

\section{Acknowledgments}

This work has been supported by HUBAK (the scientific research projects commission of Harran University, Sanliurfa, TURKEY) under project number 14170. The authors are grateful to the scientific research projects commission of Harran University for financial support.

\section{References}

[1] S.A. Boussaa, A. Kheloufi, N.B. Zaourar, F. Kerkar, Acta Phys. Pol. A 130, 133 (2016).

[2] J. Sehgal, S. Ito, J. Am. Ceram. Soc. 81, 2485 (1998).

[3] S.M. Parra-Arciniega, A. Alvarez-Mendez, L.C. Torres-Gonzalez, E.M. Sanchez, Rev. Mex. Fis. 55, 32 (2009).

[4] J.S. Lee, C.K. Hsu, Thermochim. Acta 333, 115 (1999).

[5] G.R. Anstis, P. Chantikul, B.R. Lawn, D.B. Marshall, J. Am. Ceram. Soc. 64, 533 (1981).

[6] B. Aktas, M. Albaskara, S. Yalcin, K. Dogru, Acta Phys. Pol. A 131, 511 (2017).

[7] M.K. Narayanan, H.D. Shashikala, J. Non-Cryst. Solids 430, 79 (2015). 